\title{
STUDIES ON AUTONOMIC BLOCKADE. I. COMPARISON BETWEEN THE EF- FECTS OF TETRAETHYLAMMONIUM CHLORIDE (TEAC) AND HIGH SELECTIVE SPINAL ANESTHESIA ON BLOOD PRESSURE OF NORMAL AND TOXEMIC PREGNANCY ${ }^{1}$
}

\author{
By N. S. ASSALI AND HARRY PRYSTOWSKY 2 \\ (From the Department of Obstetrics, University of Cincinnati College of Medicine, and the \\ Cincinnati General Hospital, Cincinnati)
}

(Submitted for publication March 23, 1950; accepted, July 18, 1950)

Previous studies have indicated that autonomic blockade with tetraethylammonium chloride produces different effects in normal term pregnancy and in toxemia of pregnancy (1-4). In the former, a fall in the blood pressure to very low levels occurs, while in the latter the blood pressure fall is negligible. This led to the belief that in normal pregnancy the blood pressure is maintained mainly by neurogenic impulses, while in toxemic pregnancy the blood pressure is supported principally by humoral mechanisms. It was also suggested that a certain degree of venous pooling might be a contributing factor in the blood pressure fall following autonomic blockade with TEAC.

Since recent reports $(5-8)$ on the treatment of toxemia of pregnancy with spinal anesthesia have indicated that a marked hypotension is usually observed, why then would the effect of autonomic blockade with TEAC and spinal anesthesia be different on toxemic hypertension? This question gained more strength in the face of the conflicting opinions regarding the extent of the blocking action of TEAC as compared to that of spinal anesthesia or paravertebral block $(3,9-13)$.

Thus, this work was designed to compare the effect of autonomic blockade with TEAC and spinal anesthesia in normal pregnancy and toxemia of pregnancy. High selective spinal anesthesia with low concentration of procaine $(0.2 \%)$ was the technique selected for this study. This technique blocks selectively the vasoconstrictor fibers and those which mediate the pinprick sensation. It should not be confused with the more

\footnotetext{
1 This investigation was supported (in part) by research grants from The National Heart Institute, of The National Institutes of Health, Public Health Service, and from Parke, Davis and Company, Detroit, Mich.

2 Fellow in Research. Present address: Obstetrical Department, The Johns Hopkins Hospital, Baltimore.
}

extensive blockade achieved with higher concentrations of anesthetic solutions.

\section{MATERIAL}

The material consisted of 12 normal term pregnancies; 15 toxemic pregnancies (two cases with convulsive eclampsia, 11 with severe pre-eclampsia and two cases with pre-eclampsia superimposed on pre-existing essential hypertension); and five healthy, young normotensive non-pregnant females (medical students and paid volunteers). A total of 32 patients submitted to 66 high spinal and 73 TEAC tests (some of the patients had more than one test with both spinal and TEAC). The age of the patients ranged from 15 to 40 years, an average of 24.5 years. The diagnosis of pre-eclampsia and eclampsia was based on the same criteria as outlined by Brust, Assali, and Ferris (1). Of the 12 normal pregnant females, 10 patients were studied in the prepartum and postpartum periods; two refused the postpartum test. Among the toxemic group, 12 were studied in the prepartum and postpartum periods; three refused the postpartum test.

In all normal pregnant patients the prepartum tests were performed between 33 and 40 weeks' gestation. The postpartum assays were done 36 to 48 hours after delivery. Toxemic patients were studied prepartum at the height of toxemic symptoms; in the postpartum period the study was performed when all signs of toxemia had subsided (only one patient had her postpartum test while she was still toxic).

\section{METHOD}

All of the patients were on the ward, without any medication, for at least 24 hours prior to the test. None was in labor. Both TEAC and spinal anesthesia studies were conducted with the patient lying in the supine position on an operating table which was maintained always in the horizontal position. Tilting of the table to obtain changes in the anesthetic level was not done because the anesthetic solution used was practically isobaric and its simple diffusion and dispersion in the spinal fluids were sufficient to obtain the desired level. The blood pressure was recorded by a mercury sphygmomanometer attached to one arm and maintained at heart level. Pulse rate was recorded at either radial or carotid artery. 
The patient was first submitted to the TEAC 8 test, following the technique described by Brust, Assali and Ferris (1).

The spinal test was conducted in the following manner:

(a) After the TEAC test, an interval varying from four to 24 hours was observed. During this time the patient was kept at bed rest in an isolated room in order to obtain, as much as possible, a stable blood pressure.

(b) After this stabilization period, a control blood pressure period, consisting of five to seven one-minute readings, with the patient in the supine position, was obtained before the spinal puncture was performed.

(c) With the patient in the sitting position, a spinal puncture was done, usually between $\mathrm{L}^{3}$ and $\mathrm{L}^{4}$, using a 16 gauge Tuohy needle. After the needle had reached the subarachnoid space, a polyethylene catheter was introduced cephalad to levels varying from $\mathrm{L}^{1}$ to $\mathrm{T}^{0}$ and the needle removed. The catheter was attached to a 10 cc. syringe, and the patient was returned to the supine position.

(d) The blood pressure was allowed to stabilize for another five minutes.

(e) A control one-minute cold pressor test, consisting of the immersion of the hand to the wrist in cold water $\left(+4^{\circ}\right.$ C. $)$, was performed during which blood pressure readings were taken every 15 seconds. The highest reading observed within that minute was taken as the maximum vasopressor response to the cold exposure. Then, four to five minutes were allowed to elapse until the blood pressure had returned to its original level.

(f) Procaine solution of $0.2 \%$ in saline was injected through the catheter at intervals of four to five minutes. The first dose varied from 5 to $8 \mathrm{cc}$. Subsequent doses depended on the anesthetic level and the fall in blood pressure. The former was determined by the disappearance of the pinprick sensation, using for segmental dermatome levels the criteria set forth by Foerster (14) (the supraclavicular space was taken as indicating sensory anesthesia at $\mathrm{C}^{4}$ ). In every case procaine administration was continued until the sensory anesthesia had reached levels between $T^{2}$ and $C^{3}$. Blood pressure readings were taken at one-minute and sometimes halfminute intervals. Pulse rate and motor activity of both upper and lower extremities were checked and recorded at frequent intervals.

Of the 15 toxemic patients who were tested with $0.2 \%$ procaine solution, five received additional prepartum spinal tests with $1 \%$ solution, in order to detect any difference in the effect of higher concentrations. When repeated spinal tests were performed on the same patient, an interval of 12 to 24 hours between each test was allowed to elapse. The catheter was left in the spinal canal to obviate a second spinal puncture.

(g) In order to ascertain the effectiveness of the blockade of the autonomic vasoconstrictor impulses with selective spinal anesthesia, a second one-minute cold pres-

8 Tetraethylammonium chloride (Etamon) was furnished by Parke, Davis and Company, through the courtesy of Dr. E. C. Vonder Heide. sor test was performed when the sensory anesthesia had reached levels between $T^{3}$ and $C^{3}$. The patient was interrogated as to any difference between the first and second cold sensation. When motor paralysis of the arms occurred as a consequence of the use of high concentration of procaine ( $1 \%$ solution), the second cold pressor test was either deferred or considered insignificant. After the second cold pressor test, blood pressure and pulse recordings were continued for another 10 to 20 minutes.

In cases where the blood pressure fell to dangerous levels with spinal anesthesia and the patient's condition seemed seriously affected, raising the legs 90 degrees was the only measure used to improve the patient's condition. The rationale for this maneuver will be discussed in the following report. At no time were vasoconstrictor drugs administered.

In order to compare TEAC and spinal results, a spinal "floor" was taken as being the arithmetic mean of the three lowest blood pressure readings obtained while the level of anesthesia was at $C^{4}$. This criterion was adopted because the blood pressure fall in spinal anesthesia was longer and showed more variation than TEAC; there-

TABLE I

Data on blood pressure changes of five normotensive nonpregnant subjects with TEAC and high selective spinal blockade

NORMOTENSIVE, NON-PREGNANT FEMALES

\begin{tabular}{|l|c|c|c|c|c|c|}
\hline NAME & $\begin{array}{c}\text { MEAN } \\
\text { CONTRQ } \\
\text { B.P. }\end{array}$ & $\begin{array}{c}\text { "FLEOC } \\
\text { L.E. }\end{array}$ & $\begin{array}{c}\text { PERCENT } \\
\text { FALL }\end{array}$ & $\begin{array}{c}\text { MEAN } \\
\text { CONTRO } \\
\text { B.P. }\end{array}$ & $\begin{array}{c}\text { SPINAL } \\
\text { "FLOOR" }\end{array}$ & $\begin{array}{c}\text { PERCENT } \\
\text { FALL }\end{array}$ \\
\hline D.D. & $111 / 70$ & $108 / 68$ & $3 / 3$ & $111 / 71$ & $104 / 68$ & $6 / 4$ \\
I,T. & $120 / 76$ & $110 / 70$ & $8 / 8$ & $111 / 70$ & $108 / 68$ & $3 / 3$ \\
P.B. & $120 / 68$ & $108 / 64$ & $10 / 6$ & $120 / 69$ & $114 / 64$ & $6 / 7$ \\
\hline F.M. & $103 / 70$ & $106 / 76$ & $-3 /-9$ & $105 / 71$ & $100 / 70$ & $5 / 1$ \\
\hline MEAN & $116 / 70$ & $106 / 69$ & $8 / 2$ & $114 / 71$ & $106 / 68$ & $7 / 4$ \\
\hline
\end{tabular}

The mean control blood pressure represents the arithmetic mean of several one-minute readings taken before and after the control cold pressor test, while the patient was at rest. The readings taken during the cold exposure were not included. The TEAC "floor" represents the lowest point to which the blood pressure has descended within the first five minutes following the injection. The spinal "floor" represents the arithmetic mean of the three lowest blood pressure readings when the sensory level of anesthesia was at $\mathrm{C}^{4}$. Blood pressure in $\mathrm{mm}$. of Hg. 


\section{TEAC AND HIGH SPINAL "FLOOR"IN NORMOTENSIVE NON-PREGNANT FEMALES}

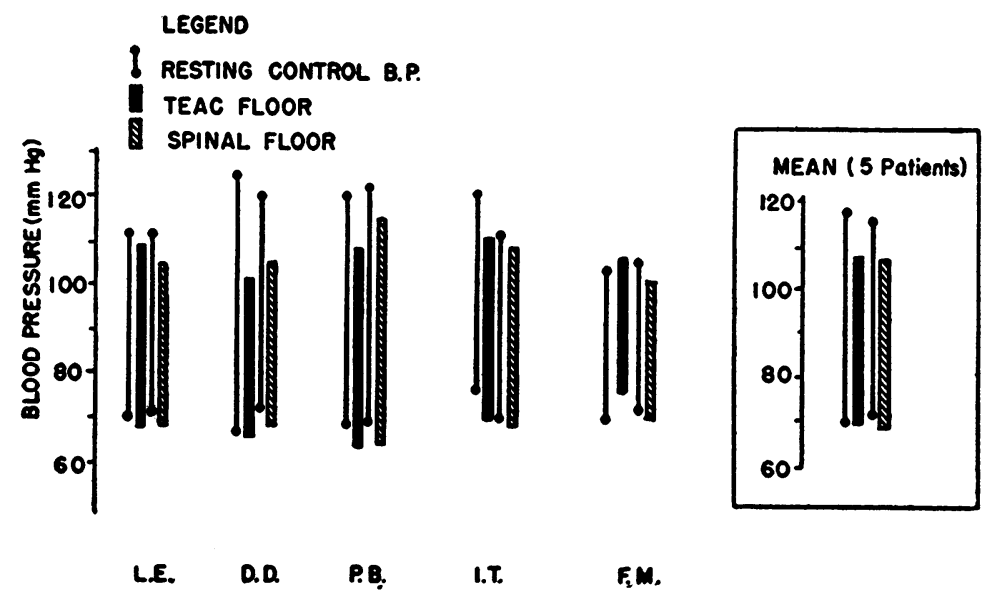

Fig. 1. TEAC and Spinal "Floors" in Five Normotensive Non-Pregnant SUBJECTS

The thin line represents the resting control blood pressure as defined in the footnote of Table I. The heavy black line represents the TEAC "floor" and the crossed line the spinal "floor." Note the negligible response to both autonomic blocking agents.

fore, the lowest reading which represents the TEAC "floor" was considered insufficient to express the spinal "floor."

\section{RESULTS}

\section{(A) Normotensive non-pregnant females}

(1) Blood pressure and pulse rate: In these subjects, the effect of autonomic blockade with high selective spinal anesthesia did not differ materially from that of TEAC. There was a negligible fall in blood pressure to both agents (Table I and Figure 1). The pulse rate remained unchanged with high selective spinal blockade, but increased with TEAC.

(2) Side effects: The normotensive group tolerated well the blockade with high selective spinal anesthesia. Two subjects had vomiting despite the absence of hypotension. Sensation of warmth over the entire body and tingling of the legs and arms were frequent. Postspinal headache occurred in all.

(3) Cold pressor test: An elevation in both systolic and diastolic pressures, varying from $\mathbf{5}$ to $25 \mathrm{~mm}$. of $\mathrm{Hg}$, was obtained. This pressor response was eliminated or was of less magnitude in the second cold pressor exposure (Figure 2).

\section{(B) Normal term pregnancy}

(1) Blood pressure and pulse rate: This group showed a striking difference from the preceding one in the response to both autonomic blocking agents. In the prepartum period, a dramatic fall in the blood pressure occurred. Although apparently the hypotension with TEAC was of less magnitude than that with spinal, it was found that only the diastolic difference was of statistical significance (Table IV). The mean prespinal control blood pressure was 120/79 mm. of $\mathrm{Hg}$ and the mean spinal "floor" was $68 / 37$, a mean fall of $43 / 53 \%$. The mean TEAC fall was $36 /$ $37 \%$. These figures were also in striking contrast with those obtained in the postpartum tests which were closely similar to the non-pregnant group ('Table II and Figure 3 ).

The length of the hypotensive effect of spinal anesthesia varied considerably. In general, following the maximum vasodepressor response, which occurred usually when the upper sensory level of anesthesia was between $\mathrm{T}^{6}$ and $\mathrm{C}^{4}$, the blood pressure started to rise spontaneously after approximately 10 to 20 minutes, even though the level of anesthesia was still high. Additional amounts of anesthetic solution given when the 

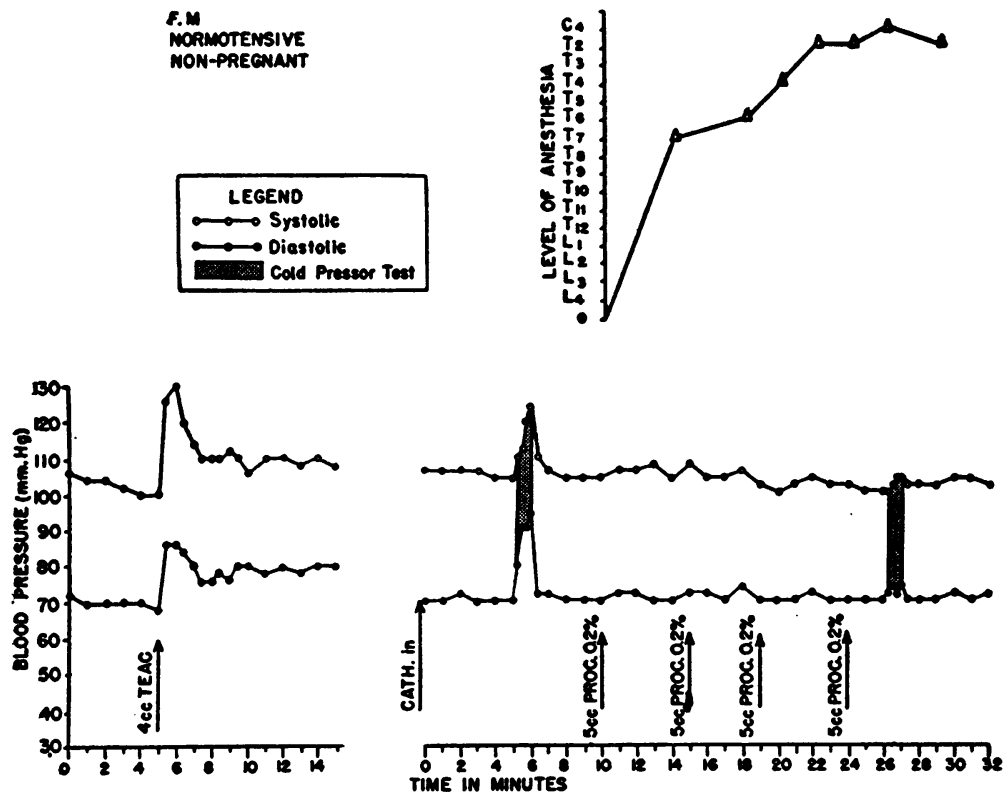

Fig. 2. Normotensive Non-Pregnant Subject Submitted to TEAC and High Spinal Tests

Note the elimination of the vasopressor response to the cold test after the spinal blockade. Twenty cc. of procaine $(0.2 \%)$ were needed to achieve a blockade to $\mathbf{C}$.

TABLE II

Date on blood pressure changes of 12 normal term pregnancies with TEAC and high selective spinal blockade in the prepartum and postpartum periods

NORMAL PREGNANCY

\begin{tabular}{|c|c|c|c|c|c|c|c|c|c|c|c|c|}
\hline \multicolumn{7}{|c|}{ PREPARTUM } & \multicolumn{6}{|c|}{ POSTPARTUM } \\
\hline NAME & $\begin{array}{l}\text { MEAN } \\
\text { CONTROL } \\
\text { B. P. }\end{array}$ & "FLOOR. & $\begin{array}{l}\text { PERCENT } \\
\text { FALL }\end{array}$ & $\begin{array}{c}\text { MEAN } \\
\text { CONTROQ } \\
\text { B.P. }\end{array}$ & $\begin{array}{l}\text { SPINAL } \\
\text { "FLOOR" }\end{array}$ & $\begin{array}{l}\text { PERCENT } \\
\text { FALL }\end{array}$ & $\begin{array}{l}\text { MEAN } \\
\text { CONTAOL } \\
\text { B.P. }\end{array}$ & TEAC & $\begin{array}{l}\text { PEACENT } \\
\text { FALL }\end{array}$ & $\begin{array}{l}\text { MEAN } \\
\text { CONTRO } \\
\text { B.P. }\end{array}$ & $\begin{array}{l}\text { SPIMAL, } \\
\text { "ROOR" }\end{array}$ & $\begin{array}{l}\text { PERCENT } \\
\text { FALL }\end{array}$ \\
\hline aw. & 122/81 & $70 / 44$ & $43 / 46$ & $126 / 93$ & $40 / 20$ & $60 / 78$ & $119 / 00$ & $114 / 83$ & $4 / 7$ & $114 / 92$ & corse & $30 / 43$ \\
\hline H. G. & 117178 & $42 / 30$ & $64 / 62$ & $102 / 69$ & $50 / 30$ & $51 / 57$ & $122 / 70$ & $104 / 60$ & $15 / \mathrm{M}$ & $116 / 74$ & $98 / 66$ & $15 / 11$ \\
\hline F. $\mathrm{H}$. & $130 / 71$ & $72 / 40$ & $46 / 44$ & $124 / 72$ & $00 / 30$ & $56 / 50$ & $132 / 70$ & $110 / 64$ & $17 / 8$ & 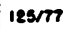 & $100 / 60$ & $20 / 12$ \\
\hline ง. B. & $134 / 96$ & $00 / 50$ & $40 / 40$ & $125 / 63$ & $48 / 30$ & $62 / 64$ & $127 / 62$ & $120 / 100$ & $6 / 2$ & $130 / 67$ & 120180 & wo \\
\hline L.H. & $118 \mathrm{rro}$ & $04 / 42$ & $29 / 40$ & $126 / 84$ & $20 / 45$ & $37 / 46$ & $100 / 78$ & $92 / 66$ & $18 / 13$ & $107 / \pi$ & $110 / r e$ & $-3 /-1$ \\
\hline v. S. & $108 / 70$ & $94 / 62$ & $13 / 82$ & $123 / 20$ & oves & 27110 & $1111 / 80$ & $110 / 80$ & 110 & $116 / 83$ & $100 / 70$ & INE \\
\hline M. o. & $108 / 71$ & $70 / 40$ & $36 / 44$ & $114 / 74$ & $60 / 20$ & $40 / 62$ & $122 \pi 3$ & $120 / 00$ & $2 /-10$ & $124 \pi$ & 100/60 & $13 / 21$ \\
\hline D. Wo. & $120 / 72$ & $62 / 40$ & $48 / 44$ & $128 / 87$ & $70 / 50$ & $45 / 43$ & $121 / 71$ & $116 / 72$ & $4 /-1$ & $126 / 72$ & $120 / 70$ & $8 / 3$ \\
\hline D. $\mathrm{m}$. & $123 / 70$ & $80 / 60$ & $30 / 23$ & $113 / 7 i$ & $70 / 20$ & serte & $136 / 21$ & $130 / 80$ & $-1 / 1$ & iअ/90 & 1200/en & evt \\
\hline G. D. & $100 / 70$ & sors6 & $\pi / 5$ & $125 / 84$ & $100 / 60$ & 21/20 & 11073 & $112 / 70$ & $-2 / 4$ & $124 / 7$ & $102 / 70$ & ievo \\
\hline M.N. & $122 / 74$ & $70 / 42$ & $43 / 43$ & $124 / 77$ & $70 / 40$ & $44 / 40$ & & & & & & \\
\hline $\mathbf{M} \mathbf{M}$. & $112 / 00$ & N2No0 & $16 / 12$ & $115 / 60$ & $30 / 20$ & $87 / 71$ & & & & & & \\
\hline MEAN & $119 / 78$ & $76 / 40$ & $36 / 37$ & $120 / 7$ & $60 / 37$ & 43/53 & $181 / 70$ & |114/73 & $6 / 4$ & $121 / 81$ & $106 / n$ & $12 / 12$ \\
\hline
\end{tabular}

For full explanation see footnote of Table I. 
TEAC AND HIGH SPINAL"FLOOR" IN NORMAL TERM PREgNANCY

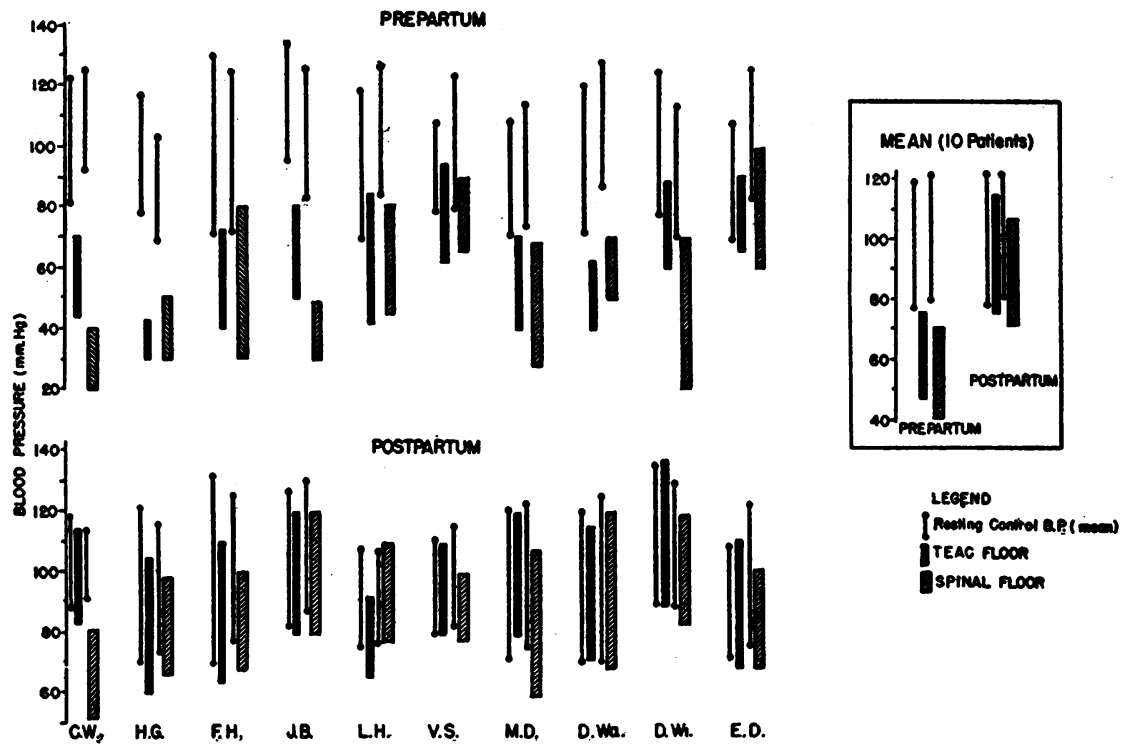

Fig. 3. TEAC and Spinal "Floors" of 10 Normal Term Pregnancies

In the upper part is the prepartum test and in the lower part the postpartum test. In the inset is shown the mean for the entire group. Note the striking difference between the prepartum and postpartum "floors."

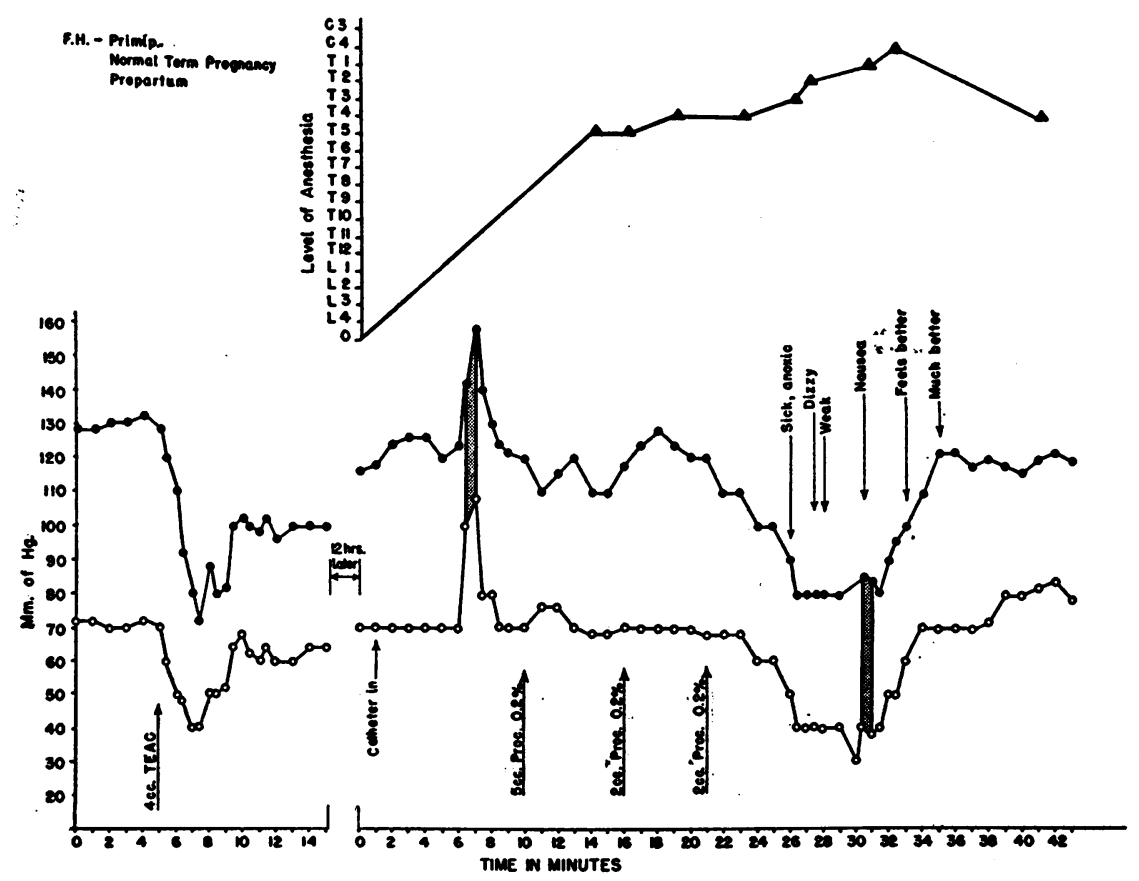

Fig. 4. Normal Pregnant Subject Submitted to TeaC and Spinal Blockade

Note the higher magnitude of the control cold pressor test as compared to that of Figures 2 and 5; also the return of the blood pressure to control levels while the level of anesthesia was still high. Note the difference between the amount of procaine given in the prepartum test and that given in the postpartum test of the same case (Figure 5) and to the normotensive non-pregnant subject (Figure 2). 
blood pressure began to ascend, reinvoked a certain degree of vasodepressor action, but it was consistently of less magnitude than before, although the anesthetic levels were the same.

The amount of procaine given to the pregnant females in the prepartum test varied from 5 to 20 cc. of $0.2 \%$ solution, which was sufficient to obtain anesthetic levels up to $\mathrm{C}^{4}$ and marked hypotension in all cases. This was in contrast with the postpartum test of the same patients, with the non-pregnant females and with the toxemic patients who required three or four times that quantity to obtain the same anesthetic level (Figures 4 and 5).

The pulse rate showed some variations. In the majority of cases, there was an increase in the pulse rate at the onset of the blood pressure fall, but at the height of the hypotension the pulse rate descended from 10 to 30 beats per minute below the control levels. The bradycardia was always concomitant with the appearance of severe hypotension and side effects. With the return of the blood pressure to its control levels the pulse ascended to its original rate.

(2) Side effects: At the height of the depressor response with the prepartum spinal test, nausea, vomiting, dizziness, weakness, fatigue, yawning, generalized numbness, perspiration of the forehead, cyanosis, hyperpnea, and other signs of imminent collapse occurred in all the patients. Sphincter relaxation was occasionally observed. All of these symptoms subsided when the lower extremities were raised 90 degrees, or when the blood pressure returned spontaneously to its original levels. None of them was observed with TEAC, even when the same hypotensive levels were obtained. They were also absent or of less intensity in the postpartum period.

(3) Cold pressor test: A vasopressor reaction to the cold exposure, varying from 10 to $50 \mathrm{~mm}$. of $\mathrm{Hg}$ in both systolic and diastolic pressures, was observed. It was consistently much higher than that seen in the postpartum test, or in the normotensive non-pregnant females. The pressor re-
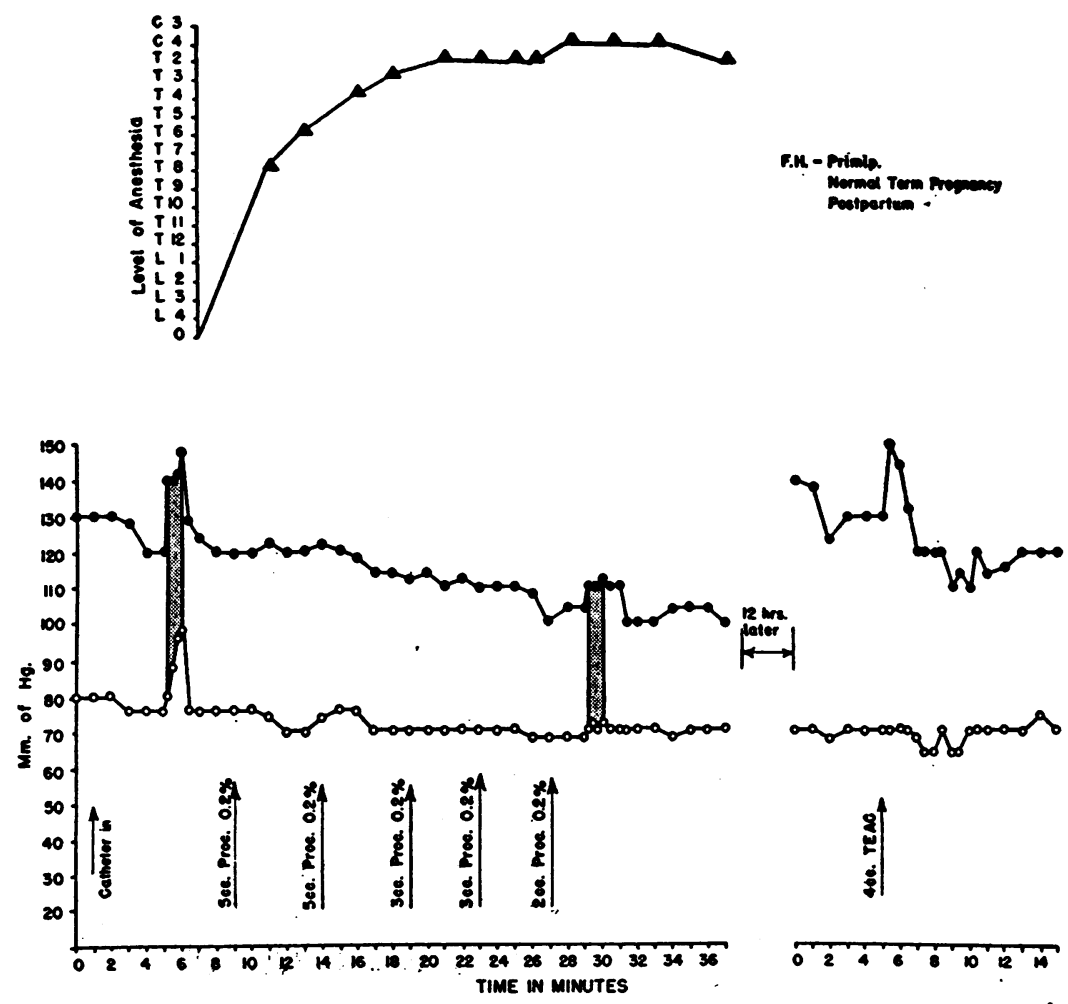

Fig. 5. Postpartum TeaC and Spinal Tests of the Same Patient of Figure. 4

Note the lack of hypotension despite the amount of procaine given being larger. 
TABLE III

Data on blood pressure changes of 15 toxemic pregnancies with TEAC and high selective spinal blockade in the prepartum and postpartum periods TOXEMIC PREGNANCY

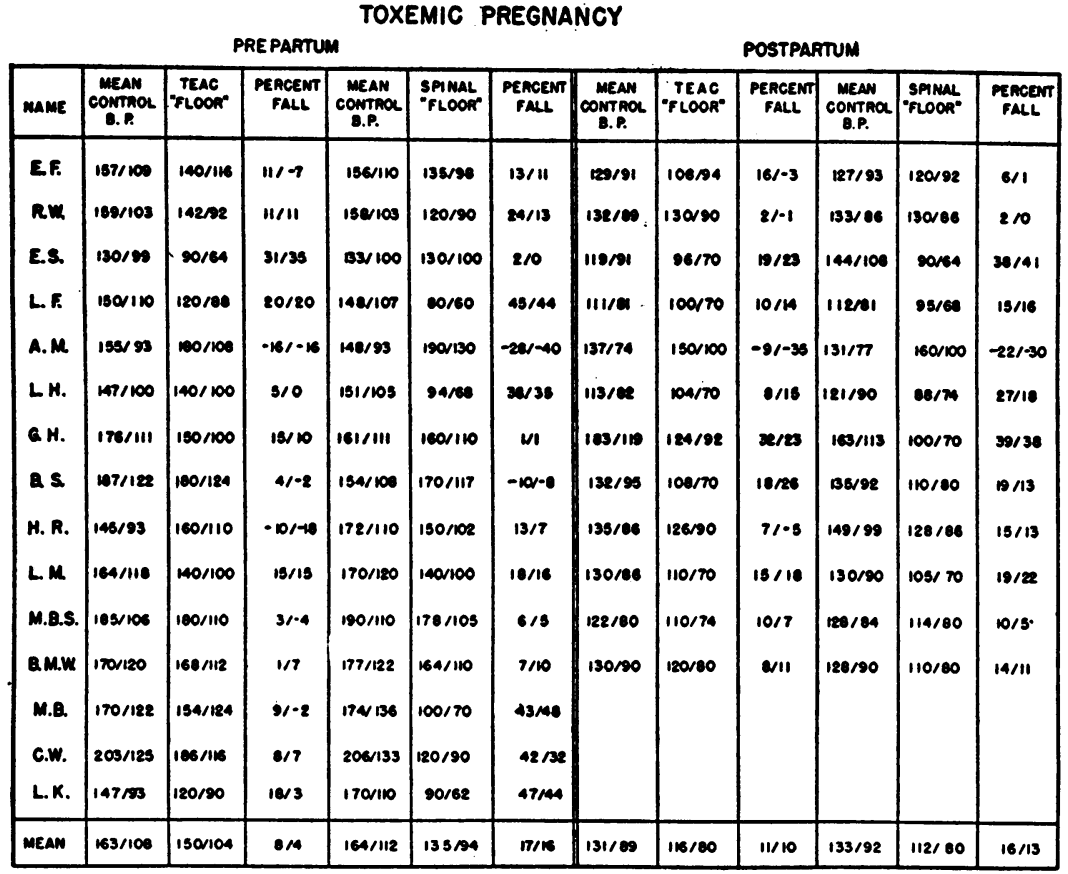

For more details see footnote of Table I.

action was also either abolished or of much less magnitude at the height of spinal anesthesia (Figure 4).

\section{(C) Toxemic pregnancy}

(1) Blood pressure and pulse rate: In this group, high selective spinal and TEAC results were also parallel, both in the prepartum and postpartum periods, although a statistically insignificant difference was encountered (Table IV). Furthermore, they were strikingly different from those observed in normal pregnancy.

The response of toxemic hypertension to high selective spinal anesthesia presented more individual variations than to TEAC. In the prepartum period, the mean control blood pressure was $164 / 112 \mathrm{~mm}$. of $\mathrm{Hg}$ and the mean spinal "floor" was $135 / 94 \mathrm{~mm}$. of $\mathrm{Hg}$, a mean fall of $17 / 16 \%$; the mean TEAC fall was $8,4 \%$ (Table III and Figure 6). However, of the 15 toxemic patients, 11 had a negligible fall with spinal and their response was closely comparable to TEAC; four had significant fall in blood pressure with spinal anesthesia (the diastolic pressure fell be- low 90) in contrast to the lack of fall with TEAC. Two of these four patients had pre-existing essential hypertension with superimposed preeclampsia, which might explain the fall observed with the spinal test. However, the exact reason for the divergency between the spinal and TEAC responses in these four cases is not clear. One patient had repeated rises in blood pressure, reaching levels at $38 / 42 \mathrm{~mm}$. of $\mathrm{Hg}$ over the control readings, each time she was tested with either TEAC or spinal anesthesia with $0.2 \%$ or $1 \%$ solution. The possibility of pheochromocytoma in this case was excluded by the negative benzodioxane, histamine and other specific tests; the nature of this vasopressor reaction remains unexplained.

The blood pressure responses of the three groups are compared in Figure 7.

Five toxemic patients who had negligible fall to high selective spinal anesthesia were retested or given additional amount of $1 \%$ procaine solution (see Method). In all of these five cases, the blood pressure fall was again negligible despite the fact that the anesthetic level reached $T^{2}$ and 
$\mathrm{C}^{4}$ and complete motor paralysis of the lower and upper extremities was present (Figure 8).

Slowing of the pulse rate occurred only in those patients who had a vasodepressor response to the spinal anesthesia. The average decrease in heart rate was the same as that seen in normal pregnancy.

(2) Side effects: Vomiting, fatigue, and restlessness were observed in the majority of patients. These symptoms were more severe when $1 \%$ procaine solution was used, but they were of less intensity than those observed in normal pregnant patients.

(3) Cold pressor test: The magnitude of the vasopressor response to the cold exposure was not different from that seen in normal term pregnancy. The peak of blood pressure elevation reached 10 to $50 \mathrm{~mm}$. of $\mathrm{Hg}$, which was abolished or decreased with spinal anesthesia. When the spinal test was performed with $0.2 \%$ solution of procaine, the patients reported slight, if any, change in the sensation to the cold. However, when the $1 \%$ solution was used and motor paralysis was present, the cold sensation was not felt.

\section{DISCUSSION}

Quantitative studies have been made by different investigators in essential hypertension and in normal subjects of the magnitude of autonomic blocking action of TEAC compared with that of spinal anesthesia or simple paravertebral block $(3,9-13)$. The results have not been uniform.

Hoobler and his associates (12) and others (9, 10) have found that TEAC blockade is less complete than paravertebral block. Soloff, Burnett and Bello (13) failed to find any agreement between the vasodepressor action of TEAC and spinal anesthesia while Ferris and his co-workers (3) have demonstrated a close parallelism between the blocking action of both agents. Since most of these studies were performed on patients with essential hypertension, the results could

TABLE IV

Statistical analysis of the data*

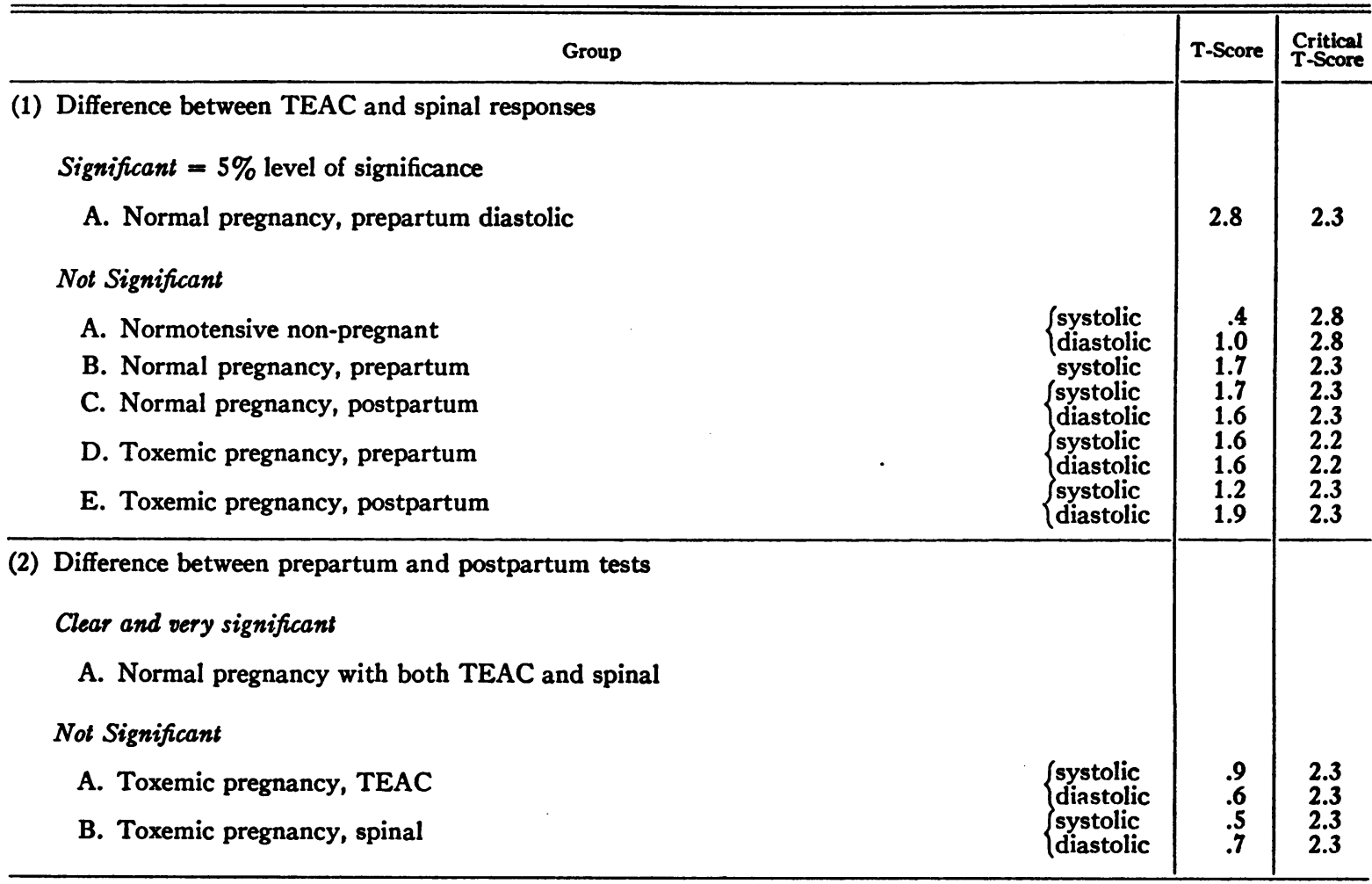

* The statistical analysis was performed by Dr. H. B. Weaver and Mr. O. D. Murphree, Department of Psychology, the University of Cincinnati, using the T-Score Method as outlined in: Lindquist, "Statistical Analysis in Educational Research." 


\begin{tabular}{|c|c|c|c|}
\hline Group & $\cdot$ & T-Score & $\begin{array}{l}\text { Critical } \\
\text { T-Score }\end{array}$ \\
\hline \multicolumn{4}{|l|}{ (3) Difference between groups in response to TEAC } \\
\hline \multicolumn{4}{|l|}{ Very Significant $=1 \%$ level of significance } \\
\hline A. Normotensive non-pregnant and normal pregnancy, prepartum & $\left\{\begin{array}{l}\text { systolic } \\
\text { diastolic }\end{array}\right.$ & $\begin{array}{r}11.6 \\
4.4\end{array}$ & $\begin{array}{l}3.0 \\
3.0\end{array}$ \\
\hline B. Normal pregnancy, prepartum and toxemic pregnancy, prepartum & $\left\{\begin{array}{l}\text { systolic } \\
\text { diastolic }\end{array}\right.$ & $\begin{array}{l}4.4 \\
5.0\end{array}$ & $\begin{array}{l}2.8 \\
2.8\end{array}$ \\
\hline \multicolumn{4}{|l|}{ Not Significant } \\
\hline A. Normotensive non-pregnant and toxemic pregnancy, prepartum & $\left\{\begin{array}{l}\text { systolic } \\
\text { diastolic }\end{array}\right.$ & .3 & $\begin{array}{l}2.1 \\
2.1\end{array}$ \\
\hline B. Normotensive non-pregnant and toxemic pregnancy, postpartum & $\left\{\begin{array}{l}\text { systolic } \\
\text { diastolic }\end{array}\right.$ & .7 & $\begin{array}{l}2.1 \\
2.1\end{array}$ \\
\hline C. Normotensive non-pregnant and normal pregnancy, postpartum & $\left\{\begin{array}{l}\text { systolic } \\
\text { diastolic }\end{array}\right.$ & .3 & $\begin{array}{l}2.2 \\
2.2\end{array}$ \\
\hline D. Normal pregnancy, postpartum and toxemic pregnancy, postpartum & $\left\{\begin{array}{l}\text { systolic } \\
\text { diastolic }\end{array}\right.$ & $\begin{array}{r}1.2 \\
.5\end{array}$ & 2.1 \\
\hline \multicolumn{4}{|l|}{ (4) Difference between groups in response to spinal } \\
\hline \multicolumn{4}{|l|}{ Very Significant $=1 \%$ level of significance } \\
\hline A. Normotensive non-pregnant and normal pregnancy, prepartum & $\left\{\begin{array}{l}\text { systolic } \\
\text { diastolic }\end{array}\right.$ & $\begin{array}{l}5.0 \\
4.9\end{array}$ & $\begin{array}{l}3.0 \\
3.0\end{array}$ \\
\hline B. Normal pregnancy, prepartum, and toxemic pregnancy, prepartum & $\left\{\begin{array}{l}\text { systolic } \\
\text { diastolic }\end{array}\right.$ & $\begin{array}{l}2.4 \\
3.6\end{array}$ & $\begin{array}{l}2.0 \\
2.8\end{array}$ \\
\hline \multicolumn{4}{|l|}{ Not Significant } \\
\hline A. Normotensive non-pregnant and toxemic pregnancy, prepartum & $\left\{\begin{array}{l}\text { systolic } \\
\text { diastolic }\end{array}\right.$ & $\begin{array}{l}1.1 \\
1.0\end{array}$ & $\begin{array}{l}2.1 \\
2.1\end{array}$ \\
\hline B. Normotensive non-pregnant and toxemic pregnancy, postpartum & $\left\{\begin{array}{l}\text { systolic } \\
\text { diastolic }\end{array}\right.$ & $\begin{array}{r}1.1 \\
.8\end{array}$ & $\begin{array}{l}2.2 \\
2.2\end{array}$ \\
\hline C. Normotensive non-pregnant and normal pregnancy, postpartum & $\left\{\begin{array}{l}\text { systolic } \\
\text { diastolic }\end{array}\right.$ & $\begin{array}{l}1.6 \\
1.5\end{array}$ & $\begin{array}{l}2.2 \\
2.2\end{array}$ \\
\hline D. Normal pregnancy postpartum and toxemic pregnancy, postpartum & $\left\{\begin{array}{l}\text { systolic } \\
\text { diastolic }\end{array}\right.$ & $\begin{array}{l}.3 \\
.02\end{array}$ & $\begin{array}{l}2.1 \\
2.1\end{array}$ \\
\hline
\end{tabular}

hardly be applied to pregnant females. Also, it is very difficult to compare the action of paravertebral block, which elicits local vasodilatation in one small segment of the body, with the general systemic action of TEAC. Furthermore, since the majority of spinal anesthesia studies were carried out with highly concentrated anesthetic solutions which produce total muscular paralysis, it is expected that such paralysis would be an added cause of error in the evaluation of spinal hypotension.

In this study, the use of high selective spinal anesthesia induced by a low concentration of procaine eliminated muscular paralysis as a possible contributing factor to spinal hypotension. It also allowed the elevation of sensory anesthesia to high levels with a consequent satisfactory autonomic blockade. Sarnoff and Arrowood (15-18) have repeatedly demonstrated that such low concentration of procaine blocks selectively the unmyeli- nated fibers, i.e., the vasoconstrictor fibers and those which mediate pinprick sensation. They also suggested that the fibers concerned with the temperature sensation might also be blocked.

That in this series a selective blockade of vasoconstrictor fibers was achieved with the spinal technique employed is evidenced by the elimination of the vasopressor reaction to the cold test. The validity of the second cold pressor test could be questioned since the sensory level of anesthesia was high enough to block all sensations to the arm. However, reliable information collected from medical students and other patients tested with both low and high concentrations of procaine strongly indicates that the low concentration did not affect the sensation to the cold exposure. Therefore, the elimination of the vasopressor reaction to the cold can only be explained on the basis of blockade of the sympathetic vasoconstrictor impulses (19). The effectiveness of the auto- 
nomic blockade could also be corroborated by the persistence of postural hypotension which was frequently observed after the spinal test had been terminated.

Thus, on the basis of these data, it should be assumed that the effects of antonomic blockade with selective spinal anesthesia and TEAC on the blood pressure are practically parallel. This parallelism was also evident when higher concentration of procaine $(1 \%)$ was used and muscular paralysis was present.

The absence of response of normotensive nonpregnant subjects to high selective spinal anesthesia confirms other studies $(20,21)$ performed with other types of spinal blockade, whereby no blood pressure changes were observed.

The results obtained in normal pregnancy with high selective spinal anesthesia further substan- tiate the hypothesis derived from experiments with TEAC that the blood pressure of such patients is supported by increased neurogenic tone and is more sensitive to the action of autonomic blockade. The latter idea is corroborated in the present study by the fact that, in the prepartum tests of normal pregnancy, much less procaine solution was required to obtain rapid changes in anesthetic and blood pressure levels than in the postpartum or normotensive non-pregnant tests. The reason for this increased sensitivity of pregnant women to autonomic block is not well understood.

Of interest also is the progressive ascent of the blood pressure after the maximum fall had occurred, even though the anesthetic level was still high. This could be interpreted as a possible lag between the recovery of vasoconstrictor and

teAC AND high SPINAL "FLOOR in tOXEMIC PREgNANCY
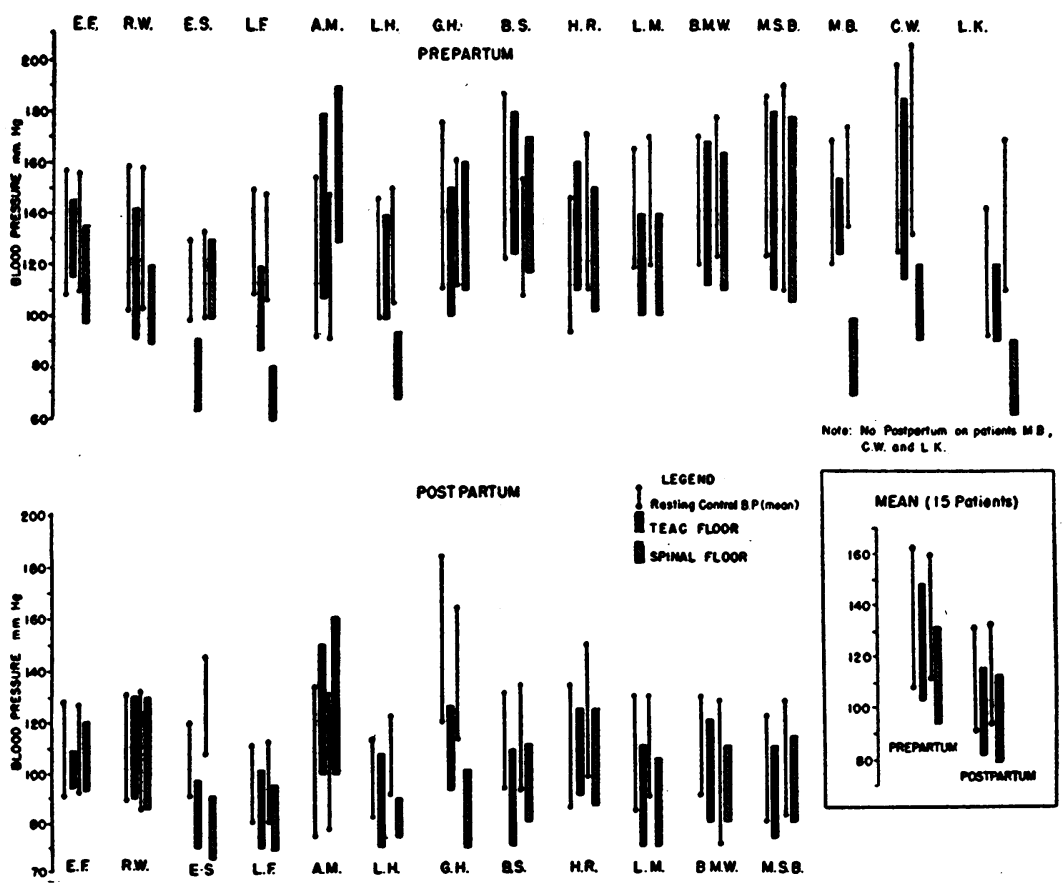

Fig. 6. TEAC and High Selective Spinal "Floors" of 15 Toxemic Patients

In the upper part is the prepartum test and in the lower part the postpartum test. Note the high "floors" in the majority of the prepartum tests and the return to normotensive levels in the postpartum period. Four patients (L. F., L. H., M. B., and L. K.) had low spinal "floors" (diastolic below $90 \mathrm{~mm}$. of $\mathrm{Hg}$ ) in contrast with high TEAC "floors." Only one subject (E. S.) had repeatedly low TEAC "floors" in contrast with high spinal "floors." One other (A. M.) had a striking rise in both TEAC and spinal "floors" each time she was tested. 
sensory fibers, since additional amounts of procaine reinduced a fall in the blood pressure. However, the possibility of compensatory mechanisms of humoral nature being stimulated by the presence of shock-like condition cannot be excluded.

The lack of blood pressure response of most toxemic patients to high selective spinal anesthesia adds more evidence to the humoral theory of toxemic hypertension. This theory has recently received more support from the results reported by Grimson and his associates $(22,23)$ whereby severe pre-eclampsia developed in pregnant patients previously submitted to extensive sympathectomy.

The present data also tend to oppose the clinical observation reported by some authors $(5-8)$ that a considerable fall in the blood pressure can be observed in all toxemic patients treated with spinal anesthesia. The fact that, in most of the cases reported large doses of barbiturates, morphine, magnesium sulfate and other sedatives were used, makes it difficult to evaluate the vasodepressor action of the spinal blockade employed.
Nevertheless, in some cases of toxemia, particularly when there is an underlying essential hypertension, a certain fall in the blood pressure might occur as was evident in some of our cases.

\section{SUMMARY AND CONCLUSIONS}

1. Comparative studies were made of the effects of autonomic blockade with TEAC and high selective spinal anesthesia on the blood pressure of normotensive non-pregnant females, normal pregnant females, and patients with toxemia of pregnancy in the prepartum and postpartum periods.

2. In all the groups studied, the effects of TEAC and high selective spinal anesthesia on the blood pressure were practically parallel.

3 . The following blood pressure changes with high selective spinal anesthesia were observed:

(a) Negligible fall in the blood pressure of normotensive non-pregnant and toxemic subjects.

(b) Marked hypotension with bradycardia and shock-like condition in the prepar-

BLOOD PRESSURE RESPONSE WITH TEAC AND HIGH SPINAL ANESTHESIA
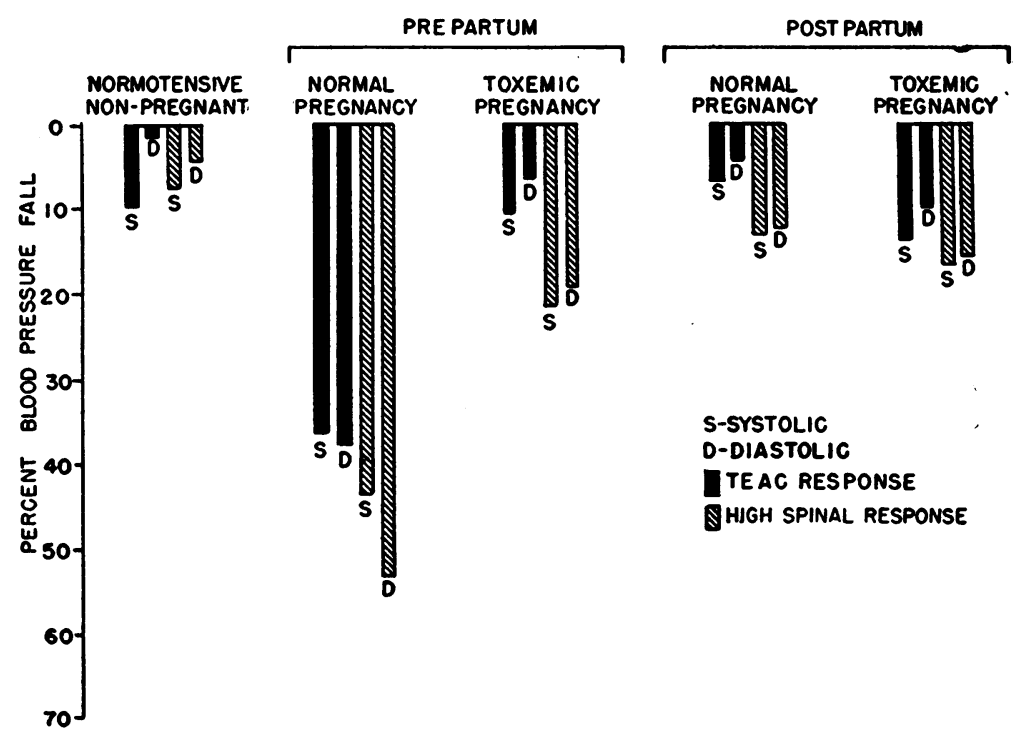

Fig. 7. Blood Pressure Responses in the Three Groups of Patients Studied with TEAC and High Spinal Blockade Plotted in Terms of Per Cent of Total Blood Pressure Fall

Note the close parallelism between TEAC and spinal results. In normal pregnancy, prepartum, only the diastolic difference was statistically significant. The low diastolic in these cases could be explained on the basis of extreme peripheral circulatory collapse which was observed in most of these patients. 


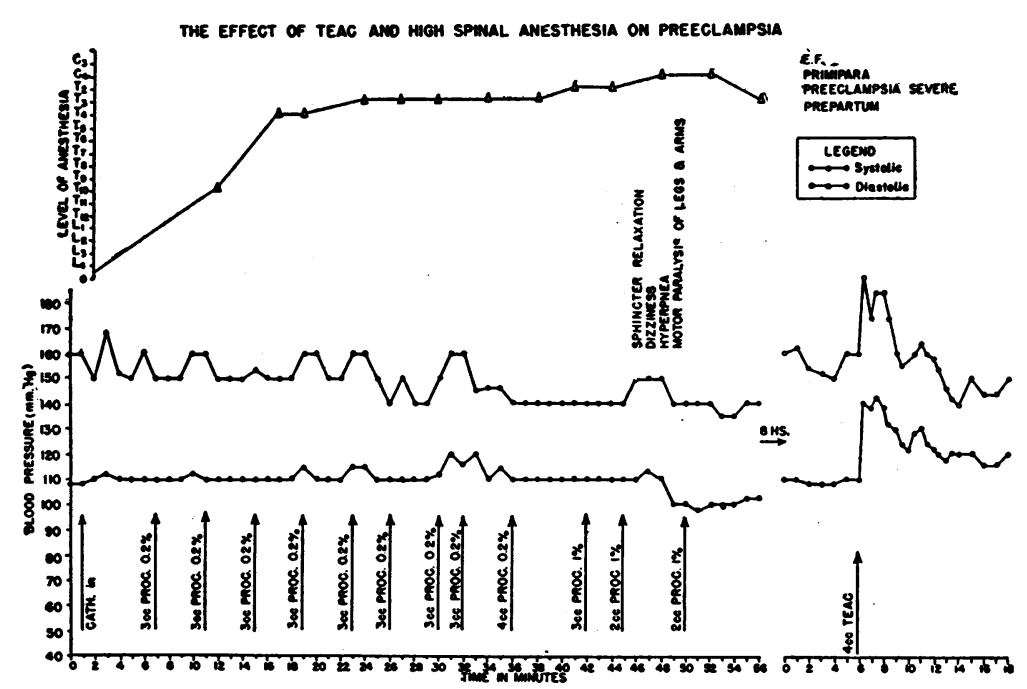

Fig. 8. A Case of Toxemic Pregnancy Submitted to a More Extensive Blockade with $0.2 \%$ and $1 \%$ of Procaine Solutions

Note the large amount of procaine given and the negligible fall in blood pressure despite complete motor paralysis of the upper and lower extremities. Respiration was maintained by $\mathrm{O}_{2}$ under pressure during the last 10 minutes of the test.

tum periods of normal term pregnancy and a return of the blood pressure responses to normotensive non-pregnant levels in the postpartum period.

4. The humoral theory of toxemic hypertension receives further support from the present study.

\section{ACKNOWLEDGMENTS}

The authors are indebted to Dr. R. W. Kistner, Dr. S. T. Garber, and other members of the Department of Obstetrics; to Drs. E. B. Ferris, Morton Reiser, Albert Brust, and A. Shapiro of the Department of Medicine; and to Dr. G. H. Acheson of the Department of Pharma. cology, for their help and constructive criticism.

\section{BIBLIOGRAPHY}

1. Brust, A. A., Assali, N. S., and Ferris, E. B., Evaluation of neurogenic and humoral factors in blood pressure maintenance in normal and toxemic pregnancy using tetraethylammonium chloride. J. Clin. Invest., 1948, 27, 717.

2. Assali, N. S., Brust, A. A., Garber, S. T., and Ferris, E. B., Comparative study of the effect of tetraethylammonium chloride and veratrum viride on blood pressure in normal and toxemic pregnancy. J. Clin. Invest., 1950, 29, 290.

3. Ferris, E. B., Reiser, M. F., Stead, W. W., and Brust, A. A., Clinical and physiological observations of interrelated mechanisms in arterial hypertension. Tr. A. Am. Physicians, 1948, 61, 97.

4. Assali, N. S., New tools for the physiologic study of hypertension in the toxemia of pregnancy. Obst. \& Gynec. Surv., 1949, 4, 605.

5. Hingson, R. A., Whitacre, F. E., Hughes, J. G., Turner, H. B., and Barnett, J. M., New horizons in the therapeutic nerve block in the treatment of vascular and renal emergencies with continuous caudal and continuous spinal analgesia and anesthesia. South. Surgeon, 1947, 13, 580.

6. Whitacre, F. E., Hingson, R. A., and Turner, H. B., The treatment of eclampsia by means of regional nerve block. South. M. J., 1948, 41, 920.

7. Lull, C. B., and Hingson, R. A., Control of Pain in Childbirth; Anesthesia, Analgesia, Amnesia. J. B. Lippincott Co., Philadelphia, 1948, 3rd Ed., pp. 123-397.

8. McElrath, P. J., Ware, H. H., Jr., Winn, W. C., and Schelin, E. C., Continuous spinal anesthesia in the treatment of severe pre-eclampsia and eclampsia, Am. J. Obst. \& Gynec., 1949, 58, 1084.

9. Boyd, A. M., Crawshaw, G. R., Ratcliffe, A. H., and Jepson, R. P., Action of tetraethylammonium bromide. Lancet, 1948, 1, 15.

10. Frisk, A. R., Hammarström, S., Lagerlöf, H., Werkö, L., Björkenheim, G., Holmgren, A., and Larsson, Y., Effect of tetraethylammonium in arterial hypertension. Am. J. Med., 1948, 5, 807.

11. Malton, S. D., Hoobler, S. W., Ballantine, H. T., Jr., Lyons, R. H., Neligh, R. B., Cohen, S. L., and Moe, G. K., Effect of autonomic blockade with 
tetraethylammonium on the blood flow in the extremities. Univ. Hosp. Bull., Ann Arbor, 1948, $14,5$.

12. Hoobler, S. W., Malton, S. D., Ballantine, H. T., Jr., Cohen, S., Neligh, R. B., Peet, M. M., and Lyons, R. H., Studies on vasomotor tone. I. The effect of the tetraethylammonium ion on the peripheral blood flow of normal subjects. J. Clin. Invest., 1949, 28, 638.

13. Soloff, L. A., Burnett, W. E., and Bello, C. T., A study of the comparative value of tetraethylammonium bromide and diagnostic spinal anesthesia in the selection of hypertensive persons for sympathectomy. Am. J. M. Sc., 1948, 216, 665.

14. Foerster, O., The dermatomes in man. Brain, 1933, $56,1$.

15. Sarnoff, S. J., and Arrowood, J. G., Differential spinal block; preliminary report. Surgery, 1946, 20, 150.

16. Sarnoff, S. J., and Arrowood, J. G., Differential spinal block. II. The reaction of sudomotor and vasomotor fibers. J. Clin. Invest., 1947, 26, 203.

17. Sarnoff, S. J., and Arrowood, J. G., Differential spinal block. III. The block of cutaneous and stretch reflexes in the presence of unimpaired position sense. J. Neurophysiol., 1947, 10, 205.
18. Arrowood, J. G., and Sarnoff, S. J., Differential spinal block. V. Use in the investigation of pain following amputation. Anesthesiology, 1948, 9, 614.

19. Reiser, M. F., and Ferris, E. B., Jr., The nature of the cold pressor test and its significance in relation to neurogenic and humoral mechanisms in hypertension. J. Clin. Invest., 1948, 27, 156.

20. Gregory, R., Lindley, E. L., and Levine, H., Studies on hypertension. II. The effect of spinal anesthesia on the blood pressure of hypertensive patients; its possible bearing on the pathogenesis of essential hypertension. Texas Rep. Biol. \& Med., 1943, 1, 167.

21. Smith, H. W., Rovenstine, E. A., Goldring, W., Chasis, H., and Ranges, H. A., Effects of spinal anesthesia on the circulation in normal unoperated man with reference to autonomy of arterioles and especially those of the renal circulation. J. Clin. Invest., 1939, 18, 319.

22. Grimson, K. S., Orgain, E. S., Anderson, B., Broome, R. A., Jr., and Longino, F. H., Results of treatment of patients with hypertension by total thoracic and partial to total lumbar sympathectomy, splanchnicectomy and celiac ganglionectomy. Ann. Surg., 1949, 129, 850.

23. Grimson, K. S., Personal communication. 